\title{
"É A PRÁTICA, A VIVÊNCIA E A CAMINHADA": A EXPERIÊNCIA DO ENCONTRO DE SABERES NA UNIVERSIDADE FEDERAL DO RIO GRANDE DO SUL
}

\author{
LUZ GONÇALVES BRITO ${ }^{1}$ \\ UFRGS, BRASIL
}

\begin{abstract}
Resumo: A inserção ampliada de estudantes negros e indígenas nas universidades brasileiras, a partir das políticas de ação afirmativa, trouxe também a extensão da reflexão sobre a necessidade de consideração, na prática pedagógica, de epistemes outras. Neste contexto, universidades no Brasil, tais como UNB, UECE, UFMG, UFJF, UFPA e UFSB, têm integrado cursos em suas grades curriculares nos quais mestras e mestres de saberes e oficios tradicionais são convidadas/os a ensinar, acompanhados por professoras/es vinculadas/os formalmente às instituições de ensino. Desde 2016-2, a disciplina "Encontro de Saberes" é oferecida pelo Departamento de Música do Instituto de Artes da Universidade Federal do Rio Grande do Sul, ressoando esse fenômeno epistemológico. Este estudo propõe-se a registar algumas experiências de docentes, mestres, mestras e discentes desde a implantação desse espaço no currículo dos cursos de graduação da UFRGS. Os procedimentos metodológicos usados foram a pesquisa de campo, leitura dos trabalhos discentes concernentes à turma 2017/2, bem como entrevistas com pessoas ligadas à realização do curso. Busca-se apreender algumas premissas concernentes ao Encontro de Saberes enquanto proposta a um só tempo étnico-racial, política, pedagógica e epistêmica.
\end{abstract}

Palavras-chave: encontro de saberes; políticas de ação afirmativa; diálogo inter-epistêmico.

Abstract: The wider inclusion of Black and Indigenous students into Brazilian universities, by means of affirmative action politics, has brought the extension of the reflection on the necessary consideration of other epistemologies in the pedagogical practice. In this context, many Brazilian universities, such as UNB, UECE, UFMG, UFJF, UFPA and UFSB have offered courses with the participation of Masters of traditional knowledges and practices. The Masters teach in association with professors formally bind to the superior education institutions. Since the second semester of 2016, the course "Encontro de Saberes" has been offered by the Department of Music of the Universidade Federal do Rio Grande do Sul (UFRGS). That course can be considered as the resonance of a larger epistemological phenomenon. This paper aims to register some experiences of teachers, Masters and students since the beginning of this space of inter-epistemic dialogue. The methodological procedures used were fieldwork; reading of student monographies related to the group of 2017 ( $2^{\text {nd }}$ semester); and interviews with people who have organized the course. This paper also aims to apprehend some premises concerning the courses Encontro de Saberes as a political, pedagogical, epistemic and ethnic-racial proposal.

Keywords: encontro de saberes; affirmative action politics; inter-epistemic dialogue.

\footnotetext{
${ }^{1}$ Doutoranda em Antropologia Social pelo Programa de Pós-Graduação em Antropologia Social da Universidade Federal do Rio Grande do Sul. E-mail: lucasgb25@gmail.com 
"Não podemos entrar na luta como objetos para nos tornarmos sujeitos mais tarde". Realmente é difícil encontrar palavras adequadas para explicar como essa afirmação era uma porta fechada - e lutei comigo mesma para encontrar a chave - e essa luta me engajou num processo transformador de pensamento crítico. Essa experiência posicionou Freire, na minha mente e no meu coração, como um professor desafiador cuja obra alimentou minha própria luta contra o processo de colonização - a mente colonizadora.

bell hooks, Ensinando a transgredir: a educação como prática da liberdade, 2013, p. 66-7.

\section{Aspectos de um contexto}

Meu interesse pela questão de epistemologias outras começou quando, ainda cursando a Licenciatura em Letras-Língua Portuguesa, participei do grupo de pesquisas em Sociolinguística Obiah - Grupo Transdisciplinar de Estudos Interculturais da Linguagem, vinculado à Universidade Federal de Goiás. Orientada pela Profa. Dra. Tânia Rezende, realizei meu trabalho de conclusão do curso, que visou a repensar metodologias de ensino de História e Cultura Afro-Brasileiras no contexto da educação básica (BRASIL, 2004). A música - mais especificamente os sambas, jongos e cantos de trabalho de escravizados cantados por Clementina de Jesus - foi trazida para a sala de aula enquanto elemento fundante da prática pedagógica. Minha pesquisa enfocou a discussão do racismo epistêmico que exclui o conhecimento proveniente da cultura afro-brasileira e africana dos espaços de ensino formal (OLIVEIRA e RODRIGUES, 2013).

No início de meu percurso acadêmico, enquanto passava pela Licenciatura em Ciências Sociais e me aproximava da Fenomenologia, que também veio a moldar meu modo de entender o mundo, eu já entendia que todo método de produção de conhecimento implica também um conjunto de premissas epistemológicas, isto é, o modo de definir as potencialidades e limites do que pode ser conhecido.

Com a passagem pelo Mestrado em Antropologia, e o estudo etnográfico das umbandas, passei a consolidar a preocupação teóricometodológica com as chamadas epistemologias nativas. Ressoando as discussões provenientes da virada ontológica (VIVEIROS DE CASTRO, 2002), pesquisei as práticas e conceitos umbandistas enquanto um sistema de conhecimento - ao qual chamei conhecimento umbandista atualizado de formas múltiplas nos diversos terreiros, tendas e centros de Umbanda. A dissertação exercitou uma metodologia que leva a sério a validade das conceptualizações próprias aos coletivos com os quais pesquisamos e assim estabelece, no caso daquele trabalho, a simetria 
entre conhecimento antropológico e conhecimento umbandista, por meio de uma "humildade epistemológica" (BRITO, 2019)².

Houve também oportunidade de me aproximar mais das práticas de produção de conhecimento que fogem a uma lógica de colonialidade do saber e escapam à racionalidade expropriadora do conhecimento construído pelas populações que geralmente interessam às pesquisas antropológicas (FABIAN, 2001). Fui monitora da disciplina de Cosmologias Indígenas no âmbito do Núcleo Takinahaky de Educação Intercultural Indígena na Universidade Federal de Goiás (UFG) ${ }^{3}$, conduzida pela Profa. Monica Pechincha.

Ainda antes de iniciar o Doutorado em Antropologia, visitei o Instituto Nacional de Ciência e Tecnologia de Inclusão no Ensino e na Pesquisa da Universidade de Brasília; assisti a duas palestras do Prof. Dr. José Jorge de Carvalho, uma na UNB e outra na UFG; e também na UFG participei como mediadora de um debate com ele, cujo tema era "Encontro de saberes e a Antropologia acadêmica hegemônica". Além disso, o Professor José Jorge esteve na banca de defesa de minha dissertação. A inspiração que esse grande intelectual no âmbito da Antropologia brasileira teve em meu percurso de formação é incomensurável e, de um modo mais amplo, certamente sua pesquisa e voz sempre serão lembradas no conjunto do fenômeno epistemológico que acompanha os movimentos de crítica ao racismo estrutural e epistêmico ainda em curso no Brasil.

As experiências do Encontros de Saberes nas universidades brasileiras têm uma história recente, mas nem por isso menos relevante. O Encontro de Saberes aparece, no Brasil, como uma prática de reflexão e intervenção crítica acerca dos modelos hegemônicos euro-americanos de produção de conhecimento.

Pode-se apontar ao menos três movimentos que contribuem para a emergência do Encontro de Saberes. Primeiro, as tentativas sucessivas de inserção de negros e indígenas nas instituições públicas de ensino por meio das políticas de ação afirmativa a partir dos primeiros anos do século XXI. Segundo, as implicações epistemológicas da presença, no espaço acadêmico, de populações historicamente subalternas. Terceiro, o questionamento das bases disciplinares rígidas características das instituições de ensino e pensamento modernos.

O primeiro está profundamente ligado ao segundo, aparecendo talvez como um movimento desdobrado em dois aspectos. Trata-se de um mesmo movimento duplo que concebe que a inserção social de populações negras e indígenas segregadas na sociedade envolvente também perpassa a consideração das epistemes próprias aos coletivos

\footnotetext{
${ }^{2}$ A humildade epistemológica refere-se a uma atitude de recusa da hierarquização entre conhecimento acadêmico e conhecimento dito "nativo". Tal hierarquização atribui estatuto e validade a um sistema de conhecimento enquanto relega o outro a um nível de mera especulação sem a sistematicidade que o conhecimento acadêmico a priori teria. A humildade epistemológica é uma atitude que reconhece a heterogeneidade dos modos de conhecer ao mesmo tempo em que busca eliminar a colonialidade do saber manifesta nos encontros entre sistemas de conhecimento e no choque cultural. Parece-me uma postura interessante para abordar o Encontro de Saberes.

${ }^{3}$ Para mais detalhes acerca da experiência contra-hegemônica do ensino intercultural na UFG, ver Oliveira e Pinto (2011); Nazareno et al. (2019); e De Castro Apinajé (2019).
} 
diferenciados. Isto é, a problematização da subalternidade epistemológica de conhecimentos culturalmente distintos corresponderia ao questionamento da exclusão étnica e racial sistemática na sociedade mais ampla (CARVALHO, 2010).

Sob um aspecto, temos as ações afirmativas como tentativa de reparar a injustiça histórica perpetrada pelo estado nacional em relação às populações indígenas e negras que, desde os primeiros fluxos coloniais, sofreram extermínio biopolítico e cultural, ou que, em decorrência dos processos de desenvolvimento econômico baseado na mão de obra de escravizados, foram posteriormente privadas de vivenciarem cidadania plena na então sociedade urbana, capitalista e estruturalmente racista (SCHWARCZ, 1993). Sob outro aspecto, temos o questionamento premente do apagamento e invisibilização dos modos de conhecer próprios às populações então excluídas e segregadas dos espaços de ensino e aprendizagem ampla e socialmente reconhecidos.

O terceiro movimento refere-se a uma reflexão acerca dos efeitos do eurocentrismo enquanto pressuposto subjacente à conformação das instituições de ensino brasileiras, surgidas no contexto da passagem do Brasil-Império para o Brasil-República e copiadas segundo o paradigma humboldtiano de fragmentação das disciplinas acadêmicas em departamentos rígidos, mas também replicadas conforme as premissas da educação liberal oriundas da Revolução Francesa (Carvalho, 2010).

Neste sentido, as concepções eurocêntricas herdadas do período colonial foram "suprimindo, invisibilizando, desqualificando e excluindo saberes provenientes de outros paradigmas civilizatórios que compõem nossas sociedades, tais como os indígenas e afrodescendentes" (INCTI, 2015, p. 10).

A consolidação do Encontro de Saberes como espaço de diálogo inter-epistêmico e de valorização das populações tradicionais em todo o Brasil tem fecundado diversos estudos sobre os desafios e alegrias epistemológicos encontrados durante processos locais de diferentes universidades, tais como a Universidade de Brasília, a Universidade Federal de Minas Gerais, a Universidade Federal do Pará, a Universidade Estadual do Ceará, a Universidade Federal de Juiz de Fora, a Universidade Federal do Sul da Bahia e, mais recentemente, a Universidade Federal do Rio Grande do Sul (doravante, UFRGS).

Não obstante as especificidades de cada instituição de ensino, pode-se em certa medida asseverar que os aspectos curriculares fundantes das súmulas dos cursos regulares dentro das matrizes institucionais abrangem quatro dimensões: a luta antirracista imbricada nas ações afirmativas; o reconhecimento dos mestres e mestras de outras culturas como detentores de "Notório Saber" e que podem ensinar sem ter adquirido diplomas por meio de educação formal; a dimensão pedagógica que alça mestras e mestres a uma posição de sujeitos de produção do conhecimento e, por fim; a premissa da

\footnotetext{
${ }^{4}$ Ver, por exemplo, anais da Reunião de Antropologia da Ciência e da Tecnologia de 2017, simpósio temático 9: Encontros de Saberes: Transversalidades e Experiências. Disponível em: https://ocs.ige.unicamp.br/ojs/react/article/view/2611/2357. Acesso em: 14 fev. 2019.
} 
transdisciplinaridade como modo de levar em consideração outros processos fenomenológicos de aprendizado, tais como a oralidade, a percepção direta, práticas corporais e expressão estética (INCTI, 2015).

Este estudo vem se somar a uma reflexão acerca do Encontro de Saberes na UFRGS já iniciada pelas próprias professoras que têm participado na condução do projeto (STEIN et al., 2019). O objetivo é apreender como algumas das premissas supracitadas são concretizadas na experiência vivida por pessoas que têm participado na implementação do Encontro de Saberes na UFRGS.

Tendo em vista que os parâmetros para os Encontros seguem, de modo geral, os documentos produzidos pelo Instituto de Inclusão na Ciência e na Pesquisa da Universidade de Brasília, o objetivo não será um exercício comparativo. Assim, neste artigo se encontra um registro singelo e circunscrito do como a experiência do Encontro de Saberes tem acontecido na UFRGS, através de textos escritos por discentes, bem como por meio de diálogos e entrevistas realizadas com algumas pessoas envolvidas na interdisciplina 5 .

A metodologia do trabalho englobou entrevistas com duas mestras e um mestre que participaram da interdisciplina (Elaine Espíndola, Iracema Gã Rã Nascimento e João Padilha) e diálogos com discentes e docentes da interdisciplina. Também houve acesso aos trabalhos e reflexões coletivos e individuais da terceira turma da disciplina Encontro de Saberes, de 2017-2, alguns dos quais são apresentados a seguir.

\section{Encontro de Saberes como experiência transformativa}

Mestra Elaine é Mestra da cura e de saberes políticos. O vasto conhecimento que carrega como bagagem cultural se liga à sua experiência vivida ${ }^{6}$. E assim como sua vida se entrelaça com a história do povo negro de Porto Alegre, é impossível referir-se à sua figura sem tocar no papel que teve o Mocambo (Associação Comunitária Amigos da Cidade Baixa e Arredores) em um conjunto de ações sociais, que renderam ao Mocambo o reconhecimento de patrimônio cultural da cidade.

O Mocambo, em seus 13 anos de história, tornou-se um território negro em Porto Alegre, ponto de irradiação cultural e de resistência da memória afro-gaúcha. Localizado em frente ao Largo Zumbi dos Palmares, na Avenida Loureiro da Silva, esse pedacinho de terra guarda muito do conhecimento e do patrimônio imaterial afro-brasileiro na região sul. É lugar de resistência pois permanece como memória da população negra que vivia nos arredores da Cidade Baixa, próxima à Ponte de Pedra.

\footnotetext{
${ }^{5}$ O Encontro de saberes na UFRGS, além de intercultural, é interdisciplinar (STEIN et al., 2019, p. 5), no sentido de que apresenta uma vinculação institucional enquanto curso ofertado oficialmente entre diferentes disciplinas.

${ }^{6}$ Estou entendendo experiência vivida no sentido que Bruner e Turner (1986) dão ao termo. Trata-se de uma sequência de sensações, pensamento, ações, reflexões pelas quais a pessoa passa através e que se completa quando a pessoa a expressa, seja por meio da narrativa, do canto ou de outra forma. Essa noção de experiência vivida é transformativa, processual, e implica a expressão do vivido para um público que ouve, lê ou acessa os pensamentos, reflexões e sentimentos.
} 
Segundo me ensinou Mestra Elaine, o povo negro, pobre e trabalhador residia ali antes da construção do viaduto da Borges de Medeiros, que foi um fator de ligação da Cidade Baixa e da parte alta da cidade, onde residia a camada aristocrática, até que no processo de mudança causado pelos projetos de urbanização de cariz higienizador, tal população foi deslocada para longe, aos bairros da zona sul da cidade.

O Mocambo permaneceu também como memória dos escravos fugidos que, conta-se, encontravam esconderijo nos matagais que havia naquela região até o século XIX. Sem casualidade, o Mocambo evoca, esteticamente, a rusticidade de um quilombo ainda existente no ambiente citadino.

Tive a honra de passar duas tardes dialogando com Mestra Elaine. Enquanto caminhávamos pelo Centro Histórico de Porto Alegre, ela me narrou os meandros do movimento social, de suas longas e literais caminhadas - foi conselheira de saúde do município e foi também uma das pessoas que participaram das homologações de terras quilombolas no Rio Grande do Sul.

Mestra Elaine me contou que se sentiu acolhida pelos professores ligados à UFRGS. Cada mestre e mestra é acompanhado por um ou uma docente que tem o papel de 'anfitrião'.

A gente se sentia à vontade, trabalhava nossa origem, mas dentro também do que não pode romper, com relação à proposta da universidade. Em nenhum momento havia a questão político-partidária, ela tem que ser uma política de resistência. E foi isso que todos nós fizemos no primeiro semestre. Daí nós passamos a cosmovisão do Mocambo e da Cidade Baixa, por que se estava falando de território (entrevista concedida à autora).

Mestra Elaine, como se vê, participou do primeiro semestre da disciplina, em 2016/2, e foi convidada novamente no outro semestre para continuar. Ela diz que, assim como os outros, se surpreendeu:

Mesmo com outros enfoques, mas sempre voltados a essa questão do imaterial, da oralidade, e o que foi melhor ainda, descobrir que essa academia também estava querendo que os seus jovens ou os mestres fossem aprender a ouvir. [...] Então nosso cuidado deve ser redobrado e ainda deve ser, por que foi um compromisso que a Mestra Iracema teve, Mestre Maurício, Mestre Jorge, de não fechar aquela porta, de deixar entreaberta para que outros pudessem trabalhar. É o que está acontecendo agora com a Janja, que é uma quilombola, urbana, mas quilombola (entrevista concedida à autora).

Perguntada sobre o conteúdo ministrado por ela, Dona Elaine respondeu: "Eu estava dizendo o quê que era a minha vivência". Segundo 
ela própria, as aulas, nos dois semestres, referiam-se principalmente ao território negro na cidade, ao qual sua vida esteve intimamente ligada, como mulher negra, cuja mãe, a Mariazinha da Praiana (escola de samba porto-alegrense), foi uma mulher que desafiou o preconceito da sociedade ao colocar as mulheres da Cidade Baixa para desfilarem em toda sua realeza negra na ala 'Verde que te quero rosa'. Sua relação familiar com a Praiana foi materializada em uma aula na qual Mestra Elaine levou alguns participantes da escola de samba para tocar a bateria.

Sobre sua relação com os alunos, além de dizer que os livros são importantes, Mestra Elaine ressalta que a oralidade deve ser respeitada, de modo que haja complementaridade entre ambas formas de produção de conhecimento. Observando esse aspecto, ela pergunta: "Cadê o ser humano conhecer com a oralidade ir e voltar com a memória no tempo, se sentar, se olhar, se ouvir?" (entrevista concedida à autora).

E tal método gerava algo diferente na expressão facial de estudantes. Como Mestra Elaine frisa, era possível para ela perceber os efeitos de suas falas "na transformação dos rostos, dos olhares. E quando terminavam as aulas, sabe aquele cercamento que vem e fazem? Às vezes uns não diziam nada, mas falavam: 'Me dá um abraço'. E daí eu via aluno se emocionar, sabia?" (entrevista concedida à autora).

Esse emocionar, envolvendo sentimento e sensações propiciadas por uma proximidade entre professora e estudante, nem sempre possibilitado dentro do ambiente acadêmico, evoca a noção do pensarsentirfazer.

Isso significa que o processo de ensinoaprendizagem não privilegia apenas o campo intelectual, convocando o corpo e os sentidos para participar no trabalho formativo. Desta maneira, a transmissão de conteúdos ocorre através das técnicas de oralidade, das práticas de observação, da manipulação e confecção de objetos, dos trabalhos de campo, dos ritmos e performances e assim por diante (INCTI, 2015, p. 13).

Além de uma humildade epistemológica, a experiência é fundamental para que possamos entender a fecundidade da interdisciplina. $\mathrm{O}$ modo de conhecer preconizado pela prática pedagógica do Encontro de saberes revela o que chamo de conhecimento vivido. $O$ processo de produção de conhecimento vivenciado através da interdisciplina Encontro de saberes - com a presença de mestres e mestras compartilhando seus saberes, que geralmente são objeto de pesquisa nas ciências humanas - desestabiliza o pressuposto cartesiano que se tornou uma das bases do pensamento euro-americano e permeia as universidades: a divisão dicotômica entre sujeito cognoscente e objeto de conhecimento. Tal divisão engendrou também uma série de binarismos, tais como mente e corpo e razão e emoção.

O sujeito do conhecimento conhece a si mesmo enquanto ser corporificado em toda a sua potencialidade no mundo. Contudo, experiência não é aqui oposta à racionalidade. A experiência não se refere 
à sensação oposta à intelecção, ao sentimento em contraposição à cognição ou ao corpo separado da mente, mas antes abrange ambos os processos de conhecimento dentro de uma racionalidade própria que não opõe percepção e cognição. Assim, o corpo está inteiramente envolvido no processo do conhecimento e não é excluído, uma vez que a experiência:

faz referência a um sujeito em ação, a um sujeito que se engaja e dela participa, que sente a ação, pensa sobre ela e a reformula. Nesse sentido, a experiência pode ser comunicada por que não implicaria apenas ações e sentimentos, mas também reflexões sobre ações e sentimentos (KOFES E PISCITELLI, 1997, p. 345).

Ao atravessar a Avenida Protásio Alves e entrar na rua que me levaria à casa de Mestra Iracema, liguei para ela e logo vi João Padilha subindo a rua para buscar a mim e duas alunas da disciplina, Camila e Giulia, com as quais me encontrei ali mesmo pela primeira vez. Estávamos todas indo visitar o casal. As alunas foram solicitar outras informações sobre a cosmovisão Kaingang, que completaria o zine (revista autônoma, de caráter informativo e crítico a problemas sociais) produzido em um grupo de sua turma na interdisciplina.

Acolhedores, Mestra Iracema e Mestre João Padilha nos receberam com sorrisos e vontade de ajudar. Apesar da simplicidade da casa, construída em madeira, os cocares e colares deixados na sala demonstravam a nobreza das pessoas que ali viviam, um cacique e uma kujá (xamã), duas importantes lideranças indígenas no sul do Brasil.

Sentadas no chão com Iracema, as estudantes leram o conteúdo do zine e, ouvindo atentos, Mestra Iracema e Mestre João Padilha apontavam um e outro termo a ser alterado e, a partir dos símbolos do sol e da lua, discorriam sobre a divisão cosmológica dualista e complementar entre kamé e kairu-kré. Enquanto isso, dialoguei com João Padilha sobre sua participação nas disciplinas da UFRGS em 2016 e 2017. Era possível perceber o entusiasmo das jovens ouvindo as explanações. As jovens pediram à neta de Mestra Iracema que desenhasse a lua e o sol, e anexaram o desenho ao zine.

Este momento criativo, envolvendo todos ali presentes, consistia em uma extensão do Encontro de Saberes, por meio da pesquisa de campo. Tratava-se de um espaço de aprendizado no qual se compartilhava experiência e conhecimento.

Mestra Iracema Gã Rã Nascimento é Mestra da cura, espiritualidade e cosmologia. Ela tem aparecido em um amplo conjunto de textos acadêmicos, como interlocutora e autora, e sua inserção na Universidade enquanto Mestra vem coroar seu trabalho - ela diria a missão mesma de ensinar a cultura indígena para os fog (brancos, não-indígenas) ${ }^{7}$.

\footnotetext{
${ }^{7}$ A respeito da trajetória e presença relevante de Mestra Iracema no contexto da etnologia ameríndia no Cone Sul, ver Nascimento et al. (2017). 
Para Mestra Iracema, é importante incluir os saberes indígenas dentro dos currículos. Ela parabeniza à UFRGS pela iniciativa. Em 2017/2, Mestra Iracema, que também tem conhecimentos relativos ao parto e auxílio ao nascimento de crianças, ministrou o curso sobre 'Plantas e Espíritos'.

Segundo Mestra Iracema, desde pequena ela foi conduzida pelos seus yangré (guias espirituais) para a tarefa de passar adiante o conhecimento indígena - é também por isso que ela dialoga tanto com intelectuais acadêmicos e tem inclusive escrito um livro sobre o cuidado com Ga (Mãe Terra). Para ela, quando estudantes cumprimentam na rua, a ela e a outros indígenas, há aí um sinal de que a sua tarefa tem sido cumprida. De certo modo, esta forma distinta de interagir com a alteridade de indígenas, propiciada pelo conhecimento adquirido por meio da experiência do Encontro de Saberes, é um aspecto daquilo que Barbosa Neto chama de "arte do respeito" (informação verbal) ${ }^{8}$.

Mestre João Padilha é Mestre de saberes políticos. Há anos envolvido no movimento indígena, ele tem participado de palestras Brasil afora e GTs para homologação de terras indígenas. Enquanto cacique Kaingang do coletivo que vive nas imediações do Morro Santana, em Porto Alegre, Mestre João Padilha tem conhecimento sobre a relação entre indígenas e não-indígenas e a experiência de diálogo sobre direitos diferenciados desde a época de construção da Constituição Federal de 1988. Além disso, continua mediando as demandas de políticas indígenas no que se refere à sua relação com a sociedade envolvente.

De certo modo, o tema das aulas que Mestre João Padilha ministrou abrange uma crítica contundente ao capitalismo enquanto sistema de valores que permeia o âmbito econômico e político dos estados-nacionais modernos. Sua crítica demonstra uma preocupação mais ampla, global, quanto ao futuro de todos que vivem no planeta. "Eles [discentes] estão no mesmo barco que nós também. Se o planeta afundar vai todo mundo junto. Não adianta ser branco, ser preto, ser amarelo, ser vermelho. E não adianta ter um banco cheio de dinheiro". E justamente por observar a interrelação entre indígenas e não-indígenas como habitantes do mundo que João Padilha diz: "A sabedoria tem que estar pra fora, para a pessoa refletir" (entrevista concedida à autora).

Quanto à sua relação com estudantes, Mestre João Padilha diz: "Muitos reagiam com surpresa. Muitos achavam que eu não sabia tudo o que a gente sabe. Ficavam surpresos por que não sou um ignorante, um selvagem". Percebeu respeito de discentes pelo seu conhecimento que, segundo ele, foi aprendido através da escuta dos mais velhos, da observação e da prática.

Mestre João Padilha se mostra alegre em perceber o interesse de estudantes em ouvi-lo. "É muito satisfatório pra gente que luta por essa causa saber que tem jovem que gosta de conversar conosco e ouvir. Porque é sinal que não vai ficar perdida, não vai ficar morta essa sabedoria" (entrevista concedida à autora). Qual sabedoria é essa a que

\footnotetext{
${ }^{8}$ Informação extraída de palestra "O Encontro de Saberes e a Arte do Respeito", proferida por Edgar Barbosa Neto em 10 de novembro de 2017, durante o I Encontros Discentes do PPGAS/UFRGS. 
ele se refere? A sabedoria do respeito às águas e ao ar, à terra e à vida. Esse respeito pela vida em seu sentido mais amplo é uma concepção cosmo-ontológica propriamente indígena e aponta que o compartilhamento dessa sabedoria corporifica uma prática (cosmo)política, na qual as premissas euro-americanas acerca das interrelações entre economia, sociedade e natureza são inexoravelmente questionadas. De forma simples, modesta, e mesmo assim e talvez exatamente por isso, potente, Mestre João Padilha demonstra que existem relações inextricáveis entre sociedade e natureza, entre humanos e ambiente.

Ouvir as ideias políticas de Mestre João Padilha implica questionar não só o exercício do poder político nas sociedades euro-americanas, mas também a própria "repartição de poderes" que entrega ao cientista o poder de falar pelas coisas da natureza (LATOUR, 2004). O pensamento modernista que serve de base para o estado nacional implica a concessão de poder político a quem se imagina deter conhecimento legítimo acerca da natureza (ou da cultura) e pressupõe um tipo de consenso acerca do estatuto ontológico da divisão entre sociedade, enquanto o mundo dos humanos, e natureza, enquanto mundo não-social. Entretanto, a repartição de poderes no estado nacional, em outro nível, também implica a divisão entre nós, euro-americanos e eles, o resto, dentre os quais são colocados os indígenas.

Um diálogo político democrático é impossível se uma das partes seja o cientista, o líder político não indígena dentro da estrutura estatal ou o estudante universitário - toma de antemão suas noções como superiores, porque científicas, e considera que a outra parte - a liderança indígena - apenas representa sua crença ilusória acerca da natureza das coisas. A distinção entre sociedade e natureza - e seus pares de opostos análogos, tais como cultura/natureza, nós/outros - é um construto ontoepistêmico euramericano que pode obnubilar uma tolerância intolerante, um respeito arrogante.

Ouvir com generosidade a generosa indagação de Mestre João Padilha provoca a noção de que a construção de um mundo comum, cujo espaço aberto pelo Encontro de Saberes permite vivenciar, precisa necessariamente recusar as noções cunhadas pelos fog como as únicas verdadeiras. Entender a validade do saber político Kaingang levanta ainda a necessidade de pensar outras formas de fazer política.

O conhecimento apresentado por cada um dos mestres tem um caráter transformativo, cujas implicações existenciais são explícitas. Por que o Encontro de Saberes catalisa a força transformativa do conhecimento? Não apenas porque os mestres e mestras trazem uma relação intrínseca com a militância, mas também porque o conhecimento vivido se torna transformativo à medida em que o gesto do conhecer se apresenta como processo de imersão perceptual, como educação da atenção e como um comprometimento com a própria vida. 
Apesar da força transformativa do Encontro de Saberes, a implantação da disciplina não aconteceu sem dificuldades, tais como:

a ausência de espaço físico próprio para o encontro do grupo até a necessidade de a disciplina ser vinculada a um departamento, contrariando a natureza transdisciplinar e intercultural da proposta. Um impasse ainda a ser equacionado envolve a criação de uma rubrica formal que viabilize 0 pagamento, como docentes, a mestres e mestras, ainda que não possuam as costumeiras vinculações profissionais e titulações acadêmicas (Jornal da Universidade, p. 2, nov. 2017)9 ${ }^{9}$.

Foi exatamente o espaço físico limitado que me foi apontado como impedimento para minha pesquisa de campo no âmbito das aulas de modo frequente. Estes problemas - em relação a espaço físico, a questões burocráticas da instituição de ensino ou mesmo o impedimento formal do pagamento de bolsa a mestres e mestras, não previsto como rubrica para os programas de fomento às atividades da universidade foram enfrentados desde o primeiro semestre em que a disciplina foi oferecida (2016/2), e continuam a preocupar as e os docentes das diversas áreas que apoiam o curso como anfitriões dos mestres e mestras convidados.

Conforme o que me disse a professora Rumi Kubo ${ }^{10}$, os recursos para a disciplina sempre foram parcos, e não foi uma vez que os professores/as responsáveis tiraram do próprio bolso para adquirir materiais necessários às atividades. Essa dificuldade, como pontuou Kubo, não parece ser enfrentada pela UFMG, por exemplo, onde existe incentivo institucional às disciplinas, sem maiores dificuldades. Caberia perguntar por que a interdisciplina Encontro de Saberes na UFRGS, mesmo reconhecida institucionalmente e integrante do currículo eletivo de todos os cursos de graduação, enfrenta esse tipo de dificuldade, enquanto se configura como uma passagem importante entre a universidade e a sociedade como um todo. Essa questão também parece sugerir uma enorme distância entre a academia e o mundo fora dela, sendo a interdisciplina Encontro de Saberes um espaço de resistência epistêmica e intercultural. Como enfatizam Stein et al. (2019):

No âmbito administrativo, muitos desafios têm sido enfrentados, e as soluções encontradas ainda são provisórias. Neste momento estamos trabalhando pela

\footnotetext{
${ }^{9}$ Ver: Jornal da Universidade. Porto Alegre, RS. Vol. 20, n. 196 (nov. 2016), p. 2. Disponível em: < https://www.lume.ufrgs.br/bitstream/handle/10183/150154/001008085.pdf?sequence=1 $>$. Acesso em 20/05/2018.

${ }^{10}$ A Profa. Rumi Kubo é doutora em Antropologia Social pelo PPGAS/UFRGS, além de bióloga e artista visual. Leciona no Departamento de Ciências Econômicas e Relações Internacionais da UFRGS. Em 2017, dialogamos presencialmente em três ocasiões, a primeira durante uma palestra de Dr. Edgar Barbosa Neto no âmbito do PGDR (Programa de Pós-Graduação em Desenvolvimento Rural); a segunda em sua participação em evento de Antropologia Visual no PPGAS; e também após a última aula da interdisciplina, a qual pude assistir.
} 
inclusão dos mestres na estrutura administrativafinanceira da UFRGS, seja por reconhecimento de seu Notório Saber e correspondente titulação, seja por vínculos institucionais alternativos que os tornem visitantes legítimos nos quadros universitários e que permitam sua certificação e o pagamento por seu trabalho (p. 9).

Sob outro aspecto, não há dúvida de que, apesar das limitações institucionais, a disciplina tem sido importante na vida de muitos discentes. Esse conhecimento vivido que transforma as pessoas também se evidencia nas falas e escritas de discentes, como veremos a seguir ${ }^{11}$.

Uma das discentes que concedeu uma entrevista foi a discente Amanda Carpenedo, que é uma violonista formada em Música pelo Instituto de Artes da UFRGS. Por meio de correio eletrônico, escreveu que experiências como aquelas propiciadas pela interdisciplina "te fazem sair da caixa e ver a vida de outra forma são realmente transformadoras". Ainda segundo ela,

foi uma experiência muito rica na minha vida, pude aprender diversas perspectivas de olhar o outro e a mim mesma, e enxergar o diferente. Num primeiro momento causa um estranhamento, visto que a abordagem da disciplina foge da maneira acadêmica usual, mas rapidamente entramos no clima e cada momento de troca de aprendizado se torna único. Experiências como esta que te fazem sair da caixa e ver a vida de outra forma são realmente transformadoras (entrevista concedida à autora).

O aspecto fenomenológico dos pressupostos pedagógicos da disciplina, que causam estranhamento, foram superados por Amanda, que considera a experiência um aprendizado da alteridade e um tipo de deslocamento de zonas de conforto intelectual, bem como alargamento de horizontes conceituais.

Esta transformação provém da força decorrente de um tipo específico de "intervenção teórico-política de corte transdisciplinar que contribui substancialmente para descolonizar o modelo de conhecimento científico, técnico e humanístico oferecido em nossas universidades" (CARVALHO e FLOREZ, 2014, p. 132, tradução nossa).

A experiência é transformativa também por que propicia a partilha de conhecimento comumente circunscrito a outras esferas da vida, tal como as técnicas e conceitos a que podemos chamar de 'espiritualidade'. É este tipo de linguagem que o relato de Camila Brum ${ }^{12}$ expressa:

\footnotetext{
${ }^{11}$ Os trabalhos individuais dos quais foram retirados os excertos foram escolhidos em decorrência da maior proximidade da pesquisadora, no contexto da pesquisa empírica, com as pessoas que os escreveram. Sob outro aspecto, enfocar as produções discentes estenderia este estudo para além do escopo definido.

12 Camila, 27 anos, estava nos últimos períodos do curso de Museologia quando participou da interdisciplina. Ela trabalha como comunicadora social vinculada à feira ecológica do Menino Deus, à Feira Quintanda e à Feira dos Agricultores Ecologistas, todas em Porto Alegre.
} 
Eu sabia que, não importa quando, eu ia me transformar [...] Quando fomos a campo, fizemos uma das trilhas oferecidas pelo quilombo, aprendemos sobre aquele território, sentimos a presença e estávamos ali, presentes. Falamos sobre o lugar sagrado - que para mim pode ser material ou imaterial, pode ser o espaço onde estamos e pode ser dentro de nós. No final da visita, Janja - com a um galinho de arruda atrás da orelha - saudou os Pretos Velhos e as Pretas Velhas que protegem, cuidam, e olham por nós. Também saudei, também pedi um axé. [...] Iracema me ensinou que devemos usufruir da ciência, mas que os saberes e toda a nossa nutrição e nossa cura, o que nos mantém vivos, vem da nossa Mãe Terra [...] Foi um lindo encontro sistêmico, cósmico, astral. Boaventura de Sousa Santos defende o pensamento epistemológico a partir da ecologia de saberes, onde cada saber existe apenas em meio a outros saberes e sempre necessita de referências de outros saberes (BRUM, 2018).

O conhecimento acerca das ervas, que Mestra Janja e Mestra Iracema possuem, abrange um aspecto espiritual e cosmológico, uma vez que as plantas, dentro de um pensamento animista e/ou analogista (DESCOLA, 2011 ), além de terem uma força, um princípio ou mesmo um tipo de alma que lhe é própria, relaciona-se por um padrão sagrado, por quê ecológico, a tudo o quanto existe sobre a Mãe Terra. E as palavras da discente demonstram essa concepção sagrada do encontro com as Mestras e com a natureza por elas defendida. Tal encontro sagrado se funda sobre uma outra percepção do ambiente, que poderia ser entendida como uma percepção sagrada do ambiente (CHIESA, 2017).

Através desse excerto do relato da discente, pode-se perceber também a importância da pesquisa de campo como metodologia dentro da disciplina. Dentro de cada módulo (Plantas e Espíritos; Artes Aplicadas; Alimento e Cura; Sociedades e Cosmovisões) há pelo menos duas idas a campo e uma aula de discussão em sala de aula. O contato direto com outras culturas engendra a produção do conhecimento corporificado, que exige uma relação concreta de proximidade com 0 objeto de conhecimento e, no caso, também com os sujeitos do conhecimento, mestras e mestres.

Outra discente, Giulia' ${ }^{13}$, em seu relato, posiciona-se reflexivamente em relação ao seu modo anterior de perceber a cidade de Porto Alegre, aprendendo a "questionar a história que nos é contada e encontrar a outra versão da narrativa. Através do ponto de vista do oprimido, será possível

\footnotetext{
${ }^{13}$ Giulia, 25 anos, cursava ainda o primeiro semestre do Bacharelado em Geografia. A aproximação com a interdisciplina lhe propiciou a realização de iniciação científica com os Quilombos Urbanos de Porto Alegre no Núcleo de Estudos de Geografia e Ambiente. Seu contato com Mestra Janja e com Mestra Iracema repercutem para além de 2017 e, depois das aulas, Giulia também se engajou em ações e movimentos relacionados ao Quilombo dos Alpes (comunidade negra urbana) e à cultura Kaingang em Porto Alegre.
} 
encontrar a realidade, as consequências e as memórias apagadas". Ainda segundo ela:

Nos encontros com os mestres pude reacender a memória e desbravar outra Porto Alegre sob novos olhares, entender que a minha cidade resiste com diversos quilombos urbanos e famílias indígenas, e que estes possuem muito para ensinar sobre seus costumes e sua relação com a Terra [...] Os encontros permitiramme o autoconhecer através da terra, desbravando novos territórios dentro de Porto Alegre pude descobrir outras culturas e formas de se viver e relacionar com o mundo. Considero este momento como a semente da curiosidade, de conhecer a verdadeira história do Brasil (SICHELERO, 2018).

Os trabalhos individuais aqui citados são produtos apreciados segundo o método avaliativo da disciplina, que leva em consideração a expressão criativa de discentes, seja por meio de textos, produções audiovisuais, artes plásticas ou performances. Há também os trabalhos coletivos, no quais são observadas não apenas as ideias acerca das experiências vividas durante o semestre, mas também a relevância social do produto para o coletivo e contexto social no qual a mestra ou mestre se insere.

\section{“É visível para quem quer ver": à guisa de conclusão}

Há registros da aventura intelectual do pedagogo e filósofo Jacotot, que em sua busca por um método de ensino e aprendizagem que conduzisse a uma emancipação da inteligência de estudantes, oferecia cursos na Université de Louvain, nos quais jovens se apertavam em salas pequenas para ouvir um mestre que dizia "É preciso que eu lhes ensine que nada tenho a ensinar-lhes" (RANCIÈRE, 2002, p. 27).

Jacotot experimentava o método do aluno, em que o professor não se colocava como o dono do saber - o 'mestre ignorante' poderia inclusive ensinar matéria que não conhecia, pois o aluno estaria livre para conhecer por si mesmo e o professor apareceria mais como um mediador.

O que essa experiência de técnicas de ensino desenvolvidas no contexto da Revolução Francesa tem que ver com a disciplina Encontro de Saberes da Universidade Federal do Rio Grande do Sul, na passagem da primeira para a segunda década do século XXI?

Para além do fato que, tão procurada quanto as aulas de Jacotot, a disciplina Encontro de Saberes no primeiro semestre recebeu 366 solicitações de matrículas, a correspondência entre esses dois contextos distintos - a moldura da educação liberal no período da Revolução Francesa e o gesto decolonial do conhecimento engendrado pelas disciplinas interculturais nas universidades brasileiras - está exatamente em sua diferença. 
Jacotot e a disciplina Encontros de Saberes demonstram que há formas diferentes de aprender e que ensino não se trata somente de 'transmissão de conhecimento', mas também, e antes, de um ato emancipatório. O mestre, quando não se coloca como o detentor absoluto do conhecimento, torna-se um mediador, um facilitador que conduz as pessoas à descoberta da potencialidade que cada uma tem de aprender a aprender.

Aparentemente, há ironia na atribuição do epíteto 'ignorante' ao mestre que, embora saiba, traz também a humildade da abertura à alteridade. E essa abertura propicia que as experiências do Encontro de Saberes gerem outros encontros, que se estendem para além das próprias aulas na universidade, na construção conjunta de projetos e cooperações. Como pensa Barbosa Neto, o Encontro de Saberes redefine o saber como um modo de encontro, como um modo de criar encontros (informação verbal) ${ }^{14}$. E neste sentido, nas experiências do Encontro de Saberes, há a conjunção entre a reflexão e a intervenção social.

Como vimos, os mestres e mestras ensinam conhecimento que guardam na memória, aprendidos pela percepção direta, através da oralidade. De certo modo, e apesar de que as premissas básicas do Encontro de Saberes postulam o processo educativo como transmissão de conhecimentos, os momentos de partilha de conhecimento que envolvem a oralidade, o corpo e o sentimento, para além dos processos cognitivos de memorização, podem ser considerados também práticas de "educação da atenção" (INGOLD, 2015).

As aulas do Encontro de Saberes, e em especial as saídas de campo, levam em consideração técnicas de ensino e aprendizagem que envolvem a pessoa inteira, e toda a potencialidade de aprender por meio de uma relação perceptual com o que se quer conhecer. É exatamente este tipo de experiência que defino como 'conhecimento vivido' e 'conhecimento corporificado', uma vez que estamos diante de um processo não somente cognitivo, mas também volitivo, emocional, sensível que exige a participação atenta da pessoa, além de um exercício da vontade de estar presente, em inteireza, para apreender as nuances da oralidade. Foi também essa atenção que me foi exigida, por exemplo, ao dialogar com Mestra Elaine, Mestra Iracema e Mestre João Padilha.

Sob outro aspecto, pode-se perceber também que a ênfase na oralidade - consistindo em uma técnica de ensino e aprendizagem própria aos mestres e mestras - não exclui os livros. Tanto Mestra Elaine como Mestra Iracema, nas entrevistas, tocaram neste ponto e na importância de traduzir o conhecimento de tradição oral para a escrita. Há, neste sentido, uma alternância e combinação entre oralidade e escrita, que se complementam (CARVALHO e ÁGUAS, 2015, p. 1025). Deste modo, os "sábios professores que tiveram estudos formais em universidades ocidentalizadas" podem conviver em regime de inclusão com "os sábios sem formação ocidentalizada regular, como xamãs, pajés, babalaôs" (idem, ibidem).

\footnotetext{
${ }^{14}$ Informação extraída da palestra "Saberes, Encontros e Transversalidades", proferida por Edgar Barbosa Neto em 29 de setembro de 2017, no Programa de Pós-Graduação em Desenvolvimento Rural da UFRGS. 
Se entendido como processo mais amplo do que memorização de conceitos, os cursos do Encontro de Saberes se apresentam como movimentos de conhecimento imbricados naquilo que Mestra Elaine chamou de "aprender a ouvir" e que lembra a noção goethiana de 'fenomenologia da natureza' (BACH JR., 2016). O Encontro de Saberes desafia o modo hegemônico de conhecer, que se fundamenta em dicotomias cartesianas e na separação das disciplinas, e abre caminho para uma relação respeitosa concreta entre pessoas, culturas e epistemes.

A potencialidade do Encontro de Saberes na universidade está na valorização dos saberes provenientes da multiplicidade de epistemologias culturais e no reconhecimento de outros sujeitos de conhecimento para além da academia. O diálogo inter-epistêmico possibilita inclusive o refinamento dos modos euro-americanos de produção de conhecimento porque questiona os 'grandes divisores' (GOLDMAN e LIMA, 1999) sobre os quais se fundamenta a hierarquia colonial de saberes, pessoas e grupos sociais. E o questionamento da colonialidade em suas diferentes facetas, pela perspectiva de uma humildade epistemológica, contribui para que sujeitos subalternizados acessem e permaneçam no ambiente científico, tenham suas experiências e conhecimento validados; e para que a educação construa emancipação e transformação, com as quais a sociedade se torna mais justa, humana. 


\section{Referências Bibliográficas}

BACH JR., Jonas. "Educação e fenomenologia da natureza: o método de Goethe". Filosofia e Educação, vol. 7, n. 3, p. 57-78, 2016.

BRASIL. Diretrizes Curriculares Nacionais para a Educação das Relações Étnico-Raciais e para o Ensino de História e Cultura Afro-Brasileira e Africana. CONSELHO NACIONAL DE EDUCAÇÃO: MEC, 2004.

BRITO, Lucas Gonçalves. O véu do congá: sobre três aspectos do conhecimento umbandista. Rio de Janeiro: Gramma, 2019.

BRUM, Camila. Monografia Final da Disciplina Encontro de Saberes. Universidade Federal do Rio Grande do Sul. 2018. [mimeo]

BRUNER, Edward; TURNER, Victor. Anthropology of Experience. Urbana \& Chicago: University of Illinois Press, 1986a. p. 3-30.

CARVALHO, José Jorge de. "Los estudios culturales em América Latina: interculturalidad, acciones afirmativas y encuentro de saberes". Tabula Rasa, n. 12, p. 229-251, 2010.

CARVALHO, José Jorge de; FLOREZ, Juliana. "Encontro de saberes: projeto para descolonizar o conhecimento universitário eurocêntrico". Nómadas, n. 41, p. 131-147, 2014.

CARVALHO, José Jorge de; ÁGUAS, Carla. "Encontro de Saberes: um desafio teórico, político e epistemológico". Em: Anais Colóquio Internacional Epistemologias do Sul: aprendizagens globais Sul-Sul, Sul-Norte e Norte-Sul. p. 1017-1027, 2015.

DE CASTRO APINAJÉ, Sheila Baxy Pereira. “A dinâmica Panhi dos temas contextuais". Articulando e construindo saberes, vol. 4, 2019.

CHIESA, Gustavo Ruiz. "À procura da vida: pensando com Gregory Bateson e Tim Ingold a respeito de uma percepção sagrada do ambiente". Revista de Antropologia, vol. 60, n. 2, p. 410-435, 2017.

DESCOLA, Philippe. "Más allá de la naturaleza y de la cultura". In: Cultura y Naturaleza, Jardín Botánico de Bogotá José Celestino Mutis, 2011.

FABIAN, Johannes. Anthropology with an attitude: critical essays. Standford University Press, 2001.

GOLDMAN, Marcio; LIMA, Tania Stolze. "Como se faz um grande divisor". In: GOLDMAN, M. Alguma antropologia. Rio de Janeiro: Relume-Dumará, 1999, p. 83-92.

INCTI. "Encontro de Saberes nas Universidades: Bases para um Diálogo Interepistêmico". Documento Técnico. 25 fls. 2015. 
INGOLD, Tim. "O dédalo e o labirinto: caminhar, imaginar e educar a atenção". Horizontes Antropológicos, vol. 21, n. 44, p. 21-36, 2015.

LATOUR, Bruno. Políticas da natureza: como fazer ciência na democracia. Bauru: EDUSC, 2004.

NASCIMENTO, Iracema Gã Rã; HERMANN, Herbert Walter; MARÉCHAL, Clémentine; PADILHA, Audissea Kapri Nascimento. "Minha missão no mundo". Espaço Ameríndio, vol. 11, n. 2, p. 336-364, 2017.

NAZARENO, Elias; ARAÚJO, Ordália Cristina Gonçalves; PEREIRA, Tamiris Maia Gonçalves. "Tempo, lugar e interculturalidade na perspectiva dos estudantes indígenas no curso de educação intercultural - UFG”. Espaço Ameríndio, vol. 12, n. 1, p. 87-113, 2019.

OLIVEIRA, Elismênnia Aparecida; PINTO, Joana Plaza. "Linguajamentos e contrahegemonias epistêmicas sobre linguagem em produções escritas indígenas". Linguagem em (Dis) curso, vol. 11, n. 2, p. 311-335, 2011.

OLIVEIRA, de Luis Fernandes; RODRIGUES, Marcelino Euzebio. "A cruz o ogó e o oxê: religiosidades e racismo epistêmico na educação básica cariosa". IN: Anais da $36^{\text {a }}$ Reunião Nacional da ANPed. 2013. Disponível em:

http://36reuniao.anped.org.br/pdfs_trabalhos_aprovados/gt21_trabalhos_pdfs/gt21_267 8 texto.pdf. Acesso em: 17 maio 2015.

STEIN, Marília Raquel Albornoz; TETTAMANZY, Ana Lucia Liberato; KUBO, Rumo Regina; PRASS, Luciana. "A interdisciplina Encontro de Saberes/UFRGS como proposta investigativa-metodológica". Anais da VII Reunião de Antropologia da Ciência e da Tecnologia. $2019 . \quad$ Disponível em: https://ocs.ige.unicamp.br/ojs/react/article/view/2719/2537. Acesso em: 26 de maio 2020 .

RANCIÈRE, Jacques. O mestre ignorante. Autêntica, Belo Horizonte, 2002.

SCHWARCZ, Lilia Moritz. "Uma história de 'diferenças e desigualdades". In: O espetáculo das raças: cientistas, instituições e questão racial no Brasil - 1870-1930. São Paulo: Companhia das Letras, 1993, p. 43-66.

SICHELERO, Giulia. Ensaio Reflexivo. Monografia Final da Disciplina Encontro de Saberes. 2018. [mimeo]

VIVEIROS DE CASTRO, Eduardo. “O nativo relativo". Mana, vol. 8, n. 1, p. 113-148, 2002. 
Recebido em: 14/02/2019* Aprovado em: 03/06/2020 * Publicado em: 11/09/2020 